\title{
O Emílio de Rousseau: uma obra de Pedagogia?
}

Fernando Bonadia de Oliveira

Doutorando em Filosofia na FFLCH da USP

\section{Resumo}

O Emílio de Rousseau é comumente apresentado como um tratado de filosofia ou como um romance. Por outro lado, nos cursos de História da Educação, este livro é estimado como um dos mais famosos e importantes livros de pedagogia moderna. O objetivo desse artigo consiste em argumentar que esta obra, sendo uma das mais relevantes para a história da filosofia, pode ser considerada, simultaneamente, uma obra pedagógica fundamental; não por ter sido escrita para satisfazer interesses prático-pedagógicos particulares, mas porque, ao ser lida ao longo dos séculos, impactou profundamente práticas e teorias clássicas da pedagogia moderna.

Palavras-chave: Educação Moderna; Pedagogia Moderna; Ensino de História da Educação.

\begin{abstract}
Rousseau's Emile is commonly presented as a treatise of philosophy or as a romance. Otherwise, the History of Education courses estimate this book as one of the most famous and important books of modern pedagogy. The aim of this article is to argue that this work, being one of the most relevant to the history of philosophy, can be considered, simultaneously, a fundamental pedagogical work; not for being written to satisfy particular practical pedagogical interests, but because, being read through the centuries, it had a profound impact on practices and classical theories of modern pedagogy.
\end{abstract}

Key-words: Modern Education; Modern Pedagogy; Teaching of History of Education.

Filosofia e Educação - ISSN 1984-9605 - Volume 4, Número 2

Outubro de 2012 - Março de 2013 


\section{Introdução}

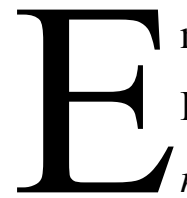

m 1760, ano em que Palissot exibiu sua comédia Os filósofos em Paris, expondo Rousseau ao ridículo, Diderot escreveu $A$ religiosa, retratando os infortúnios de uma jovem submetida a contragosto à vida monástica. Voltaire, que havia publicado em 1759 o polêmico Cândido, tornaria públicas suas desavenças com Rousseau em 1761, dois anos antes de publicar seu Tratado sobre a tolerância. Em meio a estas e a outras agitações filosóficas, culturais e políticas que assaltavam a Europa desse período, foi redigida uma obra volumosa, o Emílio.

Lançada poucos meses depois do Contrato social, o Emílio foi, no entender de Rousseau, a melhor e a mais importante de todas as suas obras ${ }^{1}$. Aplaudido no particular, mas rejeitado publicamente, o livro foi elaborado, finalizado e publicado em um tempo de transformações históricas decisivas para a vida política e cultural da modernidade. Tendo sido execrado oficialmente em Paris e em Genebra, ele conduziu o autor à condenação, obrigando-o à fuga e ao abandono de sua vida tranquila.

$\mathrm{O}$ ano de publicação do Emílio é descrito pelo filósofo genebrino como o momento em que começa a se desenrolar a "tenebrosa teia" que o enlaçaria praticamente até o fim da vida (ROUSSEAU, s/d, p. 384). Doente, migrando de país a país, sem aquela independência de outrora, carecendo da proteção daqueles de quem pouco gostava, o filósofo terá de mudar, por conta dos certames envolvendo seu tratado de educação, os planos para os novos escritos, atendo-se apenas à redação de textos apologéticos (MARQUES, 2005, p. 12-13). A expectativa do autor de não precisar mais

${ }^{1}$ No livro XI d'As confissões, Rousseau escreveu: "A publicação daquele livro não se fez seguir por aqueles esplêndidos aplausos que acompanharam todos os meus trabalhos. Nenhuma outra obra teve tantos e tão grandes elogios particulares, nem tão pouca aprovação pública. O que me disseram e o que me escreveram as pessoas mais capazes de julgá-la confirmou que aquela era a melhor de minhas obras, bem como a mais importante" (s/d, p. 374).

Filosofia e Educação - ISSN 1984-9605 - Volume 4, Número 2

Outubro de 2012 - Março de 2013 
escrever, vivendo apenas do lucro das vendas de seus livros e dos soldos resultantes do trabalho com as cópias de músicas, formulada em 1758, teve de ser definitivamente esquecida (ROUSSEAU, s/d, p. 337).

O começo da composição do Emílio parece estar relacionado a eventos íntimos de suma importância e de profundo sentido afetivo para Rousseau. Os assuntos abordados na obra são alguns daqueles que lhe foram revelados pela "iluminação de Vincennes". Por outro lado, ainda se fazem presentes no imaginário comum explicações segundo as quais a composição desta obra fora animada por vontade do autor de se retratar do abandono de seus filhos; logo, ela teria sido escrita para aliviar o remorso de um "pai desnaturado" $"$.

Embora os estudos de Peter Jimack (1960) tenham defendido que, na verdade, o peso deste remorso só foi sendo sentido pelo autor no decorrer da produção do texto, é preciso ter por constante o cuidado metodológico de, ao trabalhar com o pensamento de Rousseau, compreender que a constituição de suas obras é, realmente, indissociável dos vendavais afetivos que o arrastaram por toda sua vida.

Conforme assegura Starobinski (1991, p. 11) no prólogo de seus ensaios sobre Rousseau, esse filósofo

[...] não consentiu em separar seu pensamento e sua individualidade, suas teorias e seu destino pessoal. É preciso considerá-lo tal como se apresenta, nessa fusão e nessa confusão da existência e das ideias. Assim, somos levados a analisar a criação literária de Jean-Jacques como se ela representasse uma ação imaginária, e seu comportamento, como se ele constituísse uma ficção vivida.

\footnotetext{
${ }^{2}$ Rousseau discute a imagem de pai desnaturado na nona caminhada dos Devaneios do caminhante solitário (1986, p. 118).
} 
Considerando este entendimento como fundamental para as análises aqui levadas a efeito, pretende-se doravante mostrar como o Emílio, apesar de ter sido produzido para explicitar e tratar, de modo geral, questões filosóficas, converteu-se, enfim, ao longo dos anos e dos séculos posteriores à morte do autor, não só em um verdadeiro tratado de pedagogia, mas em um modelo de texto pedagógico, insistentemente imitado, corrigido, aprofundado e desenvolvido por uma série de grandes teóricos modernos da educação, entre os quais se destaca Pestalozzi.

Aqui será examinado o Emílio a partir de seu período de gestação, o impacto cultural de sua publicação, bem como as conseqüências daí procedentes: as duas defesas do livro na forma de cartas, uma publicada em 1763 (Carta a Christophe de Beaumont) e outra em 1764 (Cartas escritas da montanha, em resposta a Tronchin) $)^{3}$, bem como o romance inacabado Emílio e Sofia ou Os solitários, iniciado por volta de $1762^{4}$.

Deve-se esclarecer que não se intenta explorar todos os aspectos (filosóficos e/ou pedagógicos) suscitados por suas obras, mas perceber, em termos sumários, o percurso que Rousseau trilhou com elas e a maneira pela qual ele influiu na história da pedagogia.

\section{O Emílio e o ensino de história da educação e da pedagogia}

Entendendo ou não o Emílio como um texto pedagógico, o fato é que as ideias deste livro e de seu autor se fazem sempre presentes nos cursos de formação de professores e, em especial, nos cursos de Pedagogia. Seja na disciplina de filosofia ou de história da educação, o pedagogo em formação se depara com a constatação de que o Emílio é um tratado de educação

\footnotetext{
3 Tronchin havia publicado as Cartas escritas do campo, humilhando Rousseau e maldizendo suas concepções religiosas.

${ }^{4}$ Ver, sobre o início da redação desse romance, Walter Carlos Costa (1994, p. X).

Filosofia e Educação - ISSN 1984-9605 - Volume 4, Número 2

Outubro de 2012 - Março de 2013
} 
importante e fundamental para o bom entendimento da história das ideias pedagógicas.

O estudo muito completo e rico de Nacarato (2008) sobre o lugar de Rousseau nos cursos brasileiros de formação docente entre 1946 e 1996 indica que este filósofo se faz presente no campo da educação como um daqueles autores considerados imprescindíveis, como Platão e Comênio, embora ele não tenha pretendido construir receitas para práticas educativas propriamente ditas.

Segundo Nacarato (2008, p. 213), a presença de Rousseau nos cursos de formação de professores, tanto no corpo dos documentos oficiais, quanto nos capítulos de livros didáticos de História da Educação e na voz dos egressos, embora tenha sido sempre muito enfatizada, incide no reducionismo e na distorção do pensamento deste filósofo.

Lamentando o fato de que seja muito diminuto o número de educadores que passou por leituras de obras como A República, a Didática Magna e o Emílio, Nacarato (2008, p. 102) recorda, com sagacidade, que no caso da obra de Rousseau a leitura é, muitas vezes, afastada pelos professores em formação por se julgar que o abandono dos filhos pelo autor torna a obra de somenos importância.

Não é incomum ouvirmos, ainda hoje, de alunos de História da Educação críticas a esse respeito. Para esses alunos, o fato de Rousseau não ter educado seus próprios filhos - pois os abandonou na 'roda' - torna-se um motivo emocional para refutar o estudo deste autor (NACARATO, 2008, p. 104).

A distorção e a redução que, segundo a autora, são impostas ao Emílio podem ser efetivamente combatidas pelos formadores de professores, tanto pela a desconstrução da opinião de que Rousseau é um autor sem legitimidade pessoal para escrever sobre criança, quanto pela insistência por

Filosofia e Educação - ISSN 1984-9605 - Volume 4, Número 2

Outubro de 2012 - Março de 2013 
uma leitura integral da própria obra (para além do que informam os manuais). A autora, porém, não observa que a redução e a distorção correspondem ao que há de mais comum em qualquer manual e em qualquer curso que se proponha tratar de um campo do conhecimento amplo como a história, a filosofia e a pedagogia. Com isso, não se percebe que talvez não deva ser a disciplina de História da Educação o único espaço do currículo para se estudar todo o pensamento de Rousseau, ou de se ler todo o Emílio, obra extensa e densa para muitos daqueles que não conhecem seus precursores e o cenário conceitual da época de sua redação.

Sob esta perspectiva, nota-se que o ensino de História da Educação não poderá, jamais, aprofundar o estudo minucioso do autor nem de sua grande obra, pois sua tarefa no currículo implica passar por muitos tempos históricos e muitos autores distintos. Além disso, como uma leitura ingênua e despreparada do Emílio não aumentaria em nada o conhecimento concreto de suas ideias, seria necessária, para uma boa apreensão de todos os cinco livros que o compõe, uma série de medidas complexas: alguma leitura dos livros de seus predecessores (pelos menos os mais fundamentais), o conhecimento do contexto histórico da concepção de infância, adolescência e educação vigente no século XVIII na França e na Europa, bem como todo um esclarecimento filosófico e literário sobre os recursos argumentativos da obra. Isso ultrapassaria as condições e os limites de qualquer curso de História (geral) da Educação.

Seja como for, antes de se recomendar ao professor em formação a leitura do Emílio, é preciso demonstrar que sua leitura pedagógica é possível, sem, contudo, omitir as razões pelas quais a obra foi composta e por qual motivo, não tendo sido escrita para instruir educadores em missões educativas determinadas, ela (contraditoriamente) instruiu historicamente os grandes educadores modernos e contemporâneos.

Filosofia e Educação - ISSN 1984-9605 - Volume 4, Número 2

Outubro de 2012 - Março de 2013 
Sem perder jamais a natureza filosófica e literária da obra, seja como "tratado" (que configura um gênero filosófico particular), ou como "romance" (que constitui um gênero literário próprio e atribui ao texto um estilo singular), deve-se agora examinar a atmosfera pedagógica e familiar que antecedeu e preparou o aparecimento deste importante livro. Isso poderá contribuir, entre outras questões, para tornar clara, ao estudante de Pedagogia, a necessidade teórica e prática não somente de uma, mas de sucessivas leituras do Emílio.

\section{Infância, família e pedagogia antes do Emílio}

Philippe Ariès (1981) afirma que até o século XII era desconhecida a representação de crianças em obras de arte, o que seria, segundo ele, um evidente sinal da ausência de atenção dada a este ser.

Até por volta do século XII, a arte medieval desconhecia a infância ou não tentava representá-la. É impossível que essa ausência se devesse à incompetência ou à falta de habilidade (p. 50). A criança (...) não estava ausente da Idade Media, ao menos a partir do século XIII, mas nunca era o modelo de um retrato, de um retrato de uma criança real (p. 56). A descoberta da infância começou sem dúvida no século XIII, e sua evolução pode ser acompanhada na história da arte e na iconografia dos séculos XV e XVI. Mas os sinais de seu desenvolvimento tornaram-se particularmente numerosos $\mathrm{e}$ significativos a partir do fim do século XVI e durante o século XVII (p. 65).

Segundo esta compreensão, a Renascença e a Modernidade foram os momentos históricos da formação de uma preocupação teórica e prática com a infância, isto é, de sua descoberta.

Elizabeth Badinter (1985), em seu clássico estudo Um amor conquistado, reconhece, junto com Ariès, que a família, até o século XVII, embora já não fosse a mesma daquela dos tempos medievais, não trazia

Filosofia e Educação - ISSN 1984-9605 - Volume 4, Número 2

Outubro de 2012 - Março de 2013 
ainda a marca da família moderna, definida pela "ternura e intimidade que ligam os pais aos filhos" (p. 53). O século XVII, declara a autora, "não reconheceu o reinado do menino-rei, centro do universo familiar" (p. 54). No decênio 1760-1770 é que, propriamente, surgiu e se estabeleceu de forma mais generalizada o sentimento terno e íntimo da infância e a clara representação do modelo familiar moderno. Badinter assegura que antes de 1760 algumas obras que incitavam os pais a amarem modernamente seus filhos já apareciam, mas foi com Rousseau e, objetivamente, com o surgimento do Emílio que se efetuou uma transformação fundamental na família, colocando o sentimento de amor materno no cerne desta renovada instituição.

O próprio Rousseau reconhecia esta ausência de atenção para com a criança, a qual se convertia em ignorância sobre sua natureza. Mesmo a presença de John Locke, com a obra Alguns pensamentos sobre a educação, de 1693, lembrada por Rousseau, não impedia que seu assunto deixasse de ser quase uma novidade 5 .

Rousseau afirmou temer que, após seu Emílio, o assunto da educação continuasse esquecido, coisa que, muito por culpa dele, não aconteceu. $\mathrm{Na}$ verdade, conforme se divulga comumente entre as histórias da pedagogia, ainda que tenha tido predecessores ilustríssimos, Rousseau promoveu uma “revolução copernicana” na pedagogia (Eby, 1970, p. 277; Hubert, 1976, p. $245)^{6}$.

Gabriel Compayré (1970, p. 5) afirmou que o espírito laico é a "primeira característica" do tempo de Rousseau em termos educacionais: as

\footnotetext{
${ }^{5}$ Locke foi procurado, em 1684, pelo amigo Edward Clarke e sua esposa, para oferecer recomendações "sobre como instruir e educar seu jovem filho". A partir de então, o pensador inglês passou a redigir cartas sobre educação ao casal; escritas de 1684 a 1691, elas foram revisadas e ampliadas pelo autor e, então, publicadas no volume Alguns pensamentos sobre educação (YOLTON \& YOLTON, 1989, p. 1).

${ }^{6}$ É preciso ter cautela com o significado da expressão "revolução". Trata-se de uma revolução copernicana somente no sentido metafórico que, na filosofia, se concebe a transformação operada por Kant no campo da teoria do conhecimento.
}

Filosofia e Educação - ISSN 1984-9605 - Volume 4, Número 2

Outubro de 2012 - Março de 2013 
congregações religiosas, ainda existentes no século XVIII, continuariam com suas atividades pedagógicas, mas perderiam lentamente o prestígio e o crédito; não seriam jamais, como antes, soberanas em matéria de educação. O espírito filosófico, nesta nova época, não desejava mais promover um mero aprimoramento educacional; o que se pretendia - "não sem temeridade" - era reconstruir, sobre novos fundamentos, a educação inteira (p. 6).

A relação entre o autor do Emílio e seus precursores - acima explicada - é, entretanto, do ponto de vista da história da pedagogia, mais tímida e discreta do que a relação entre ele e seus continuadores e críticos. Isso decorre do fato de que Rousseau, com seu tratado sobre educação, cria ainda que inconscientemente - um tratado da pedagogia moderna; não, certamente, pela causa por que foi escrito, mas pelo efeito que produziu, como será mostrado adiante.

\section{Entre a composição, a publicação e a continuação do Emílio}

Rousseau, ao se empenhar na redação do Emílio, não era um completo inexperiente na prática de pensar e de escrever sobre a educação. Além de suas vivências ensinando música, teve uma notável (embora curta e desastrosa) experiência como preceptor de duas crianças em Lyon. Essa atividade, desenvolvida no ano de 1740, resultou na produção do Projeto para a educação do senhor de Sainte-Marie ${ }^{7}$ que já evidencia um trabalho razoavelmente profundo de reflexão sobre a formação humana. Examinando tanto o princípio do Projeto, quanto as primeiras linhas do Emílio (composto quase vinte anos depois), encontra-se, desde então, a máxima de se começar a educação pelo estudo do educando.

\footnotetext{
${ }^{7}$ Doravante: Projeto.

Filosofia e Educação - ISSN 1984-9605 - Volume 4, Número 2

Outubro de 2012 - Março de 2013
} 
Rousseau, dirigindo-se ao senhor Bonnot de Mably, pai de seus alunos, assim escreveu:

[...] meu primeiro objeto deveria ser conhecer bem os sujeitos com os quais irei lidar: é no que eu, principalmente, ocupei o tempo desde o qual tenho a honra de estar em sua casa, e penso já ter, neste sentido, dados suficientes para poder traçar o plano de sua educação (1994a, p. 13) $)^{8}$.

Conforme se observa, apesar da autocrítica do próprio filósofo ao seu desempenho como professor nesta época ${ }^{9}$, a orientação fundamental de sua educação permaneceu inalterada.

Os meninos com os quais conviveu em Lyon, longe de definirem a criança ideal que seria mais tarde o Emílio, são apreendidos em suas características de personalidade, isto é, em seus "gênios" e nos conseqüentes traços de comportamento daí derivados: um é bonito, tem a inteligência bem acabada e uma alegre malícia; o outro, estúpido, vive a vadiar, a teimar e a nada aprender, tão incorrigível que quase chega a dominar o próprio mestre.

Depois de ter teorizado a educação pública no artigo sobre economia política da Enciclopedia, em 1755, Rousseau sinaliza outra menção à educação quando redige a "Carta III" de Saint-Preux a Milorde Eduardo na

\footnotetext{
${ }^{8} \mathrm{O}$ mesmo princípio aparece no prefácio da seguinte maneira: "Não se conhece a infância; no caminho das falsas ideias que se têm, quanto mais se anda, mais se fica perdido. Os mais sábios prendem-se ao que aos homens importa saber, sem considerar o que as crianças estão em condições de aprender. Procuram sempre o homem na criança, sem pensar no que ela é antes de ser homem. (...) Começai, pois, por melhor estudar vossos alunos, pois com toda certeza não os conheceis (...)" (ROUSSEAU, 2004, p. 4).

9 Lê-se essa autocrítica n'As confissóes: "Quase possuía todos os conhecimentos necessários para um preceptor e julgava que tinha jeito para isso. Durante o ano que passei em casa de Mably, tive tempo de me desenganar (ROUSSEAU, s/d, p. 177).
}

Filosofia e Educação - ISSN 1984-9605 - Volume 4, Número 2

Outubro de 2012 - Março de 2013 
quinta parte do romance $A$ Nova Heloísa ${ }^{10}$, que aborda a instrução dos filhos de Julie.

Esta obra - iniciada e acabada entre 1756 e 1758 - foi, como se sabe, um grande sucesso ao ser publicada em 1760. Rousseau, que já era lembrado por seus dois Discursos, alcançou, em meio à paixão por Sophie d'Houdetot, a reputação de grande escritor (Moretto 1994, p. 13). Terminada a impressão desta obra, Rousseau iniciou a composição de Emílio, já assistindo em Montmorency (MORNET, 1950, p. 121).

A primeira vez que Rousseau foi acometido pela ideia de elaborar um sistema de educação, data - provavelmente - da época em que viajou para visitar Diderot na prisão e, então, meditava seriamente sobre a questão proposta pela academia de Dijon. Nesta ocasião, sucedeu o famoso episódio da "iluminação de Vincennes": o pensador genebrino narrou ter sentido, a caminho da prisão, uma forte palpitação, acompanhada de falta de ar e de uma profunda agitação mental, pela qual teria avistado uma "multidão de grandes verdades".

Na segunda das Cartas a Malesherbes, escrita em janeiro de 1762, antes, portanto, de ver publicado e condenado o Emílio, Rousseau contou:

Tudo que pude guardar dessa multidão de grandes verdades que, em um quarto de hora, me iluminou sob essa árvore, foi bem esparsamente distribuído nos três principais de meus escritos, a saber: esse primeiro discurso [sobre as ciências e as artes], aquele sobre a desigualdade e o tratado de educação, obras inseparáveis e que perfazem juntas um mesmo todo (ROUSSEAU, 2005, p. 25).

A segunda menção a um projeto de escrever sobre educação apareceu n'As confissões, no momento em que Rousseau narrou uma de suas

\footnotetext{
${ }^{10}$ Nesta carta, a certa altura, lê-se: “(...) julgo seguir uma estrada nova e segura para tornar ao mesmo tempo uma criança livre, tranquila, afetuosa, dócil e isso de um modo muito simples, o de convencê-la de que é apenas uma criança" (ROUSSEAU, 1994b, 292). Esta "estrada nova" seria, sem dúvida, o caminho esquadrinhado, anos depois, no Emílio.
}

Filosofia e Educação - ISSN 1984-9605 - Volume 4, Número 2

Outubro de 2012 - Março de 2013 
mudanças, em abril de 1756. Entre os inúmeros projetos que tinha neste período, o autor destacou, em quarto lugar, a ideia de atender ao pedido de madame Chenonceaux que, receando a educação que seu marido daria a seu filho, pedira-lhe que excogitasse e compusesse uma obra sobre a educação de crianças (ROUSSEAU, s/d, p. 270). Embora não fosse este o assunto que mais lhe cativasse, a consideração pela amizade desta senhora tornava o tema, entre todos os outros projetos, o mais caro ${ }^{11}$.

Há ainda, vale lembrar, uma terceira motivação para a produção do Emílio; trata-se, porém, de uma razão bastante pragmática: Rousseau esperava - como aqui já foi adiantado - viver com os lucros das vendas dessa obra ${ }^{12}$.

A cronologia de preparação, acabamento e publicação do Emílio obedece, segundo Mornet (1950, p. 121), a seguinte ordem: iniciada no ano de 1758, em maio de 1759 Rousseau já trabalhava no quinto livro da obra; em julho de 1760 foram feitas leituras diárias da obra e, em dezembro de 1761, o volume foi impresso em Amsterdã, começando a ser distribuído em maio de 1762.

Conquanto tenha tido retornos positivos sobre a leitura da obra nos meios filosóficos (STRECK, 2008, p. 31), a recepção do tratado de educação não teve a mesma sorte nos centros políticos e ideológicos. No dia 11 de julho de 1762 a obra foi queimada em Paris e, junto com o Contrato social, foi incinerada também em Genebra; a $1^{\mathrm{o}}$ de julho Rousseau se tornou persona non grata pelo governo de Berna; em novembro, a Sorbonne executou a condenação oficial do Emílio (MORETTO, 1986, p. 7).

\footnotetext{
${ }^{11}$ Escreveu Rousseau (s/d, p. 270): "O objetivo que eu me havia proposto ao trabalhar nele [no tratado de educação] parece-me que merecia para o autor um outro destino", referindose às tristes conseqüências políticas da publicação da obra.

${ }^{12}$ N'As confissões, lê-se: "Tinha diante de mim cerca de mil escudos. O Emílio no qual eu metera as mãos quando acabei Heloísa, estava muito adiantado e seu produto devia, pelo menos, ser o dobro desta soma. Formei o projeto de colocar aquela quantia de maneira a ter uma pequena renda vitalícia que pudesse, com a minha cópia [de músicas], dar-me subsistência sem precisar escrever mais" (ROUSSEAU, s/d, p. 337).
}

Filosofia e Educação - ISSN 1984-9605 - Volume 4, Número 2

Outubro de 2012 - Março de 2013 
O filósofo empreendeu, como se sabe, ao menos duas importantes tentativas de defesa das obras citadas.

$\mathrm{Na}$ primeira, em resposta ao arcebispo de Paris, Christophe de Beaumont, que havia produzido uma carta pastoral contra o Emílio, o problema da educação não esteve no centro das discussões. A temática religiosa preponderou em todos os níveis. Apesar de aparecerem menções à educação, o assunto principal é a explicação do famoso trecho da profissão de fé do Vigário Saboiano.

Nas Cartas escritas da montanha, Rousseau rebateu a afirmação de que seu tratado de educação teria sido escrito como guia para pais, mães e professores (2006, p. 148), alegando:

[...] essa assertiva não é desculpável, posto que manifestei no prefácio e várias vezes, ao longo do livro, uma intenção bem diferente. Trata-se de um novo sistema de educação, cujo plano submeto à análise dos sábios e não de um método para os pais e as mães, com o qual nunca sonhei. Se alguma vez, por meio de imagens bem comuns, pareço dirigir-lhes as palavras, é para me fazer melhor entender ou para me explicar com menos palavras. É verdade que escrevi meu livro a partir da solicitação de uma mãe, mas essa mãe, ainda que tão jovem e tão amável, tem sabedoria e conhece o coração humano; por sua aparência é um ornamento de seu sexo e, por seu talento, uma exceção (p. 284).

Neste fragmento, Rousseau esclareceu os objetivos de sua obra, retirando - como é bem compreensível que assim fizesse - o acento filosófico-moral do livro e deixando transparente apenas seu conteúdo pedagógico. O Emílio conteria, nessa perspectiva, um novo sistema educacional a ser examinado pelos doutos, não métodos para pais e mães, o que somente pode parecer o caso em virtude das diversas imagens simples que o romance constrói. Rousseau reconhece que o livro fora idealizado após o pedido da senhora Chenonceaux, mas não que tenha sido feito para

Filosofia e Educação - ISSN 1984-9605 - Volume 4, Número 2

Outubro de 2012 - Março de 2013 
instruir a educação materna e paterna, como havia acontecido com a obra pedagógica de Locke.

Certamente, a conclusão de que o Emílio consistiria em um "guia para os pais" foi extraída do terceiro parágrafo do livro I. Nele, Rousseau (2004, p. 7) observou: "É a ti que me dirijo, terna e previdente mãe" e, em nota à palavra "mãe", adverte:

A primeira educação é mais importante e cabe incontestavelmente às mulheres. Se o autor da natureza houvesse desejado que ela coubesse aos homens, ter-lhes-ia dado leite para alimentar as crianças. Assim, falai sempre de preferência às mulheres em vossos tratados de educação, pois, além de estarem em condições de tratá-la mais de perto do que os homens e de influírem sempre mais, o êxito também lhes interessa muito mais, já que a maior parte das viúvas se acha como que a mercê dos filhos e eles então lhe fazem sentir vivamente, no bem e no mal, o efeito da maneira como foram educados (p. 7-8).

A explicação oferecida por Rousseau é bem clara: os tratados de educação devem ser escritos para as mães, porque elas são mulheres e, por natureza, estão aptas a alimentar a criança; além disso, têm maiores condições de acompanhar mais de perto o desenvolvimento infantil e, por correrem maior risco da viuvez, são elas as que mais gozarão os efeitos da educação dada à prole. Ainda que esta referência à vocação inata da mulher para a educação das crianças se circunscreva apenas à "primeira infância"13, Rousseau propõe, na verdade, um tratado filosófico sobre a educação.

A partir de 1762, com a publicação do Emílio, Rousseau se dedicou a elaborar o romance Emílio e Sofia ou Os solitários, em que impôs a seu aluno ideal, sozinho no mundo, duras provas da vida: a traição da parceira, a perda da filha e a escravidão. Esse romance nunca foi acabado, mas permite novas possibilidades para uma re-interpretação do grande tratado de

${ }^{13}$ Sobre a contribuição de Rousseau e de outros intelectuais para o avivamento do mito da mulher como educadora nata, cf. Arce (2001, p. 170-1).

Filosofia e Educação - ISSN 1984-9605 - Volume 4, Número 2

Outubro de 2012 - Março de 2013 
educação de Rousseau, uma vez que coloca o antigo aprendiz na situação de experimentar, solitariamente, as intempéries da vida em sociedade.

Como se pode depreender do que foi anteriormente dito, a publicação do Emílio teve um impacto imediato profundamente negativo; como, porém, a negatividade da leitura dessa obra esteve atrelada à situação político-religiosa dos anos 60 e 70 do século XVIII; após a Revolução Francesa, porém, foi possível uma leitura propriamente pedagógica do livro, tornando-o, como será demonstrado a seguir, um modelo de texto pedagógico.

\section{O Emílio e o nascimento de um texto pedagógico}

Pestalozzi uma vez afirmou que o Emílio, tendo sido lido apenas leitores que não estiveram à altura da qualidade de seu conteúdo, permaneceu um "livro fechado". Todavia, como observou Gilbert Py (1997, p. 584), a recepção da obra nas décadas subseqüentes a sua publicação, foi paulatinamente desvelando as ideias pedagógicas do filósofo de Genebra.

O Emílio é, conforme o autor várias vezes repetiu, um tratado. Um tratado consiste, segundo a história tem mostrado, em um texto de natureza filosófica cujo objetivo é instaurar uma nova proposição a respeito de um assunto, trazendo à luz o resultado de novas descobertas e rompendo com antigas concepções.

O Emílio é, igualmente, tido como um romance em pelo menos três instâncias: (a) como romance filosófico, uma vez que apresenta uma determinada compreensão acerca do homem e da sociedade; (b) um romance propriamente literário, enquanto Bildungsroman (romance de formação), na medida em que descreve a trajetória de aprendizado de uma criança, ainda que fíctícia (FREITAG, 1994, p. 66-91); ou (c) como 
romance pedagógico, posto que propõe novos contornos teóricos para a condução da educação humana (GHIRALDELLI, 1987, p. 14).

O próprio Rousseau discute a forma romanesca da obra no quinto livro, ao criticar as obras pedagógicas de seu tempo:

Nos tratados de educação oferecem-nos palavrórios inúteis e pedantes sobre os quiméricos deveres das crianças, e não nos dizem palavra sobre a parte mais importante e mais difícil de toda a educação, qual seja, a crise que serve de passagem da infância para a condição de homem. Se consegui tornar estes ensaios úteis por algum aspecto, foi, sobretudo, por ter-me estendido bastante sobre esta parte essencial, omitida por todos os outros, e por não me ter deixado desencorajar nesta tentativa por falsas delicadezas, nem me amedrontar por dificuldades de língua. Se eu disse o que se deve fazer, disse o que devia dizer: pouco me importa ter escrito um romance. É um lindo romance o da natureza humana. Se ele não se encontra nestas páginas, será culpa minha? Esta deveria ser a história de minha espécie; vós que a depravais, sois vós que fazeis de meu livro um romance (2004, p. 611).

Como se nota pelo excerto acima, Rousseau aproxima sua obra do paradigma de um verdadeiro "romance da natureza humana", imputando ao leitor a possibilidade de vê-lo como um romancear. Trata-se, pois, de um trabalho que teve como mérito enfrentar os assuntos esquecidos pelos tradicionais tratados de educação: a passagem da infância à adultícia.

Como bem observa Pierre Burgelin (1969, p. CXIX), somos levados, no Emílio, a uma enorme "confusão de gêneros, em uma ambigüidade que não satisfaz por completo nem o amante de aventuras imaginárias, nem o filósofo". Se, conforme argumenta Burgelin, a leitura do Emílio não agradou inteiramente nem o apaixonado por literatura, nem o leitor-filósofo, a obra parece, indubitavelmente, ter ganhado a completa afeição dos educadores, 
principalmente aqueles que desejavam sair da teoria e travar contato com a prática da educação de crianças após a Revolução Francesa ${ }^{14}$.

Kant, apesar de ser considerado filósofo e de não ter tido experiência com a prática da educação de crianças, lecionou Pedagogia na Universidade de Königsberg, depois de ter lido o Emílio entretida e reflexivamente ${ }^{15}$. Segundo Starobisnki (1991, p. 42-3), o Rousseau de Kant e de Cassirer encontra a "reconciliação da natureza e da cultura em uma sociedade que redescobre a natureza e supera as injustiças da civilização" por meio da educação. Para o autor da Crítica da razão pura, Rousseau identificou o conflito entre natureza e cultura e procurou uma solução para este problema através de um novo plano de educação.

Entretanto, não será apenas com Kant, no nível teórico da educação, que a obra de Rousseau será explorada. Pestalozzi, Froebel e Claparède é que vão, entre outros, se nutrir das linhas do Emílio para colocar em prática aquilo que Rousseau escrevera. Com isso se colocou, enfim, o grande - e talvez supremo - dilema das ciências da educação e da pedagogia moderna: a distinção entre teoria e prática e a necessidade de sua reunião.

No final do prefácio do Emílio, Rousseau advertiu que a aplicabilidade prática de seu projeto estava vinculada às contingências de cada caso prático, podendo variar infinitamente.

Assim, tal educação pode ser realizável na Suíça, mas não na França; tal outra pode sê-lo entre os burgueses, e tal outra entre os grandes. A maior ou menor facilidade de execução depende de mil circunstâncias, impossíveis de serem determinadas a não ser numa aplicação particular do método a este ou àquele país, a esta ou àquela condição. Ora, todas estas aplicações particulares, não sendo essenciais para o meu assunto, não entram em meu plano. Outros poderão, se quiserem, ocupar-se delas, cada qual para o país

\footnotetext{
${ }^{14}$ Sobre a mudança na maneira de ler o Emílio antes de depois da revolução de 1789, ver Compayré (1970, p. 151-3).

${ }^{15}$ Sobre a leitura kantiana do Emílio, cf. Mornet (1950, p. 144).
}

Filosofia e Educação - ISSN 1984-9605 - Volume 4, Número 2

Outubro de 2012 - Março de 2013 
ou Estado que tiver em vista. Para mim, basta que em toda parte onde nasceram homens se possa fazer deles o que proponho; e que, tendo feito deles o que proponho, se tenha feito o que há de melhor, tanto para eles próprios quanto para os outros. Se não cumprir este compromisso, sem dúvida terei errado; se porém cumpri-lo, será errado também exigir mais de mim, pois é só isso que prometo $(2004$, p. 6$)$.

Nesta passagem entra em discussão a efetividade prática (ou seja, "o que é realizável”) de um projeto pedagógico teórico. Rousseau defende que, dependendo dos sujeitos e das circunstâncias às quais seu sistema for submetido o resultado poderá variar. Ele admite dois tipos de variação: uma geográfica (de país a país) e outra de classe ou "condição" social (a burguesia ou "os grandes"). Na sequência, alega que os casos práticos particulares não lhe interessam, afinal, sua preocupação é tornar os homens aquilo a que ele se propõe; isso, precisamente, é o que deve se deve examinar para seu verdadeiro escopo vir a ser autenticamente avaliado ${ }^{16}$.

As aplicações práticas particulares de suas teorias - sugeriu Rousseau - poderiam ser feitas por outras pessoas (“se elas quisessem”). Conforme a história da educação evidenciou com inúmeros exemplos, foi exatamente o que vários pedagogos se puseram a fazer depois dele.

Ao que tudo indica, Johann Heinrich Pestalozzi (1746-1827) leu o Emílio no ano de sua publicação (EBY, 1970, p. 378), quando ainda frequentava a escola e estava prestes a ingressar no estudo de Filosofia e Linguística em Zurique (INCONTRI, 1996, p. 8). A obra, todos sabem, causou-lhe profundo efeito ${ }^{17}$.

O pedagogo de Zurique se decidiu por aplicar as concepções de Rousseau numa classe e numa condição social não considerada pelo autor

${ }^{16} \mathrm{O}$ problema da relação entre teoria e prática de Rousseau já foi amplamente abordado; principalmente no que diz respeito à teoria e prática políticas, cf. Fortes (1976).

${ }^{17}$ Não só Rousseau, mas os enciclopedistas de modo geral causaram forte impacto sobre Pestalozzi (VILCHES \& COZZI, 1966, p. 8). Em especial, a leitura do Emílio recebeu pedagogo uma leitura sobremaneira atenta, embora ele não lesse bem em francês (p. 12).

Filosofia e Educação - ISSN 1984-9605 - Volume 4, Número 2

Outubro de 2012 - Março de 2013 
do Emílio: o povo, e o povo miserável ${ }^{18}$. A dedicação à pobreza, marca das crianças cujo contato desfrutou no Instituto de Stans, exigiu de Pestalozzi a grande doação de si mesmo que aprendeu com mãe; Susanne, viúva quando o filho possuía apenas cinco anos, deu a ele, com seu espírito altruísta, seu maior exemplo de educador. Tendo freqüentado ainda garoto a casa de seu avô, mais distante do centro urbano, ele observou os meninos pobres que viviam, apesar da carência de dinheiro, uma vida feliz, ao contrário das crianças da cidade enclausuradas nos colégios (LUZURIAGA, 1972, p. 173; EBY, 1970, p. 375; VILCHES \& COZZI, 1966, p. 11). Esses dois elementos, a abnegação materna e a felicidade do homem simples, formaram-lhe, segundo dizem, o sentimento da pobreza.

Quando nasceu, em 1770, seu único filho, Hans Jakob - nome dado em homenagem a Jean-Jacques (INCONTRI, 1996, p. 9) - Pestalozzi passou a desejar contribuir para com as crianças pobres (EBY, 1970, p. 378). Antes de concretizar este desejo, ele publicou, quase vinte anos após o Emílio, o romance Leonardo e Gertrudes (1781), que tem como grande herói do romance a personagem Gertrudes, casada com Leonardo, um trabalhador assalariado pobre, acostumado a freqüentar a taberna, cedendo facilmente ao "vício pela bebida". Com muitos filhos, Leonardo, Gertrudes e os demais personagens do romance vivem miseravelmente, acompanhados das mais profundas "deficiências morais" daquele tempo.

A atividade educadora de Gertrudes em relação aos filhos, feita em um ambiente de vida difícil e sofrida, fez sucesso entre o público e o lucro com a venda do romance ajudou financeiramente o autor (FREITAG, 1994, p. 79), dando-lhe um resultado bem diferente daquele obtido pelo autor do Emílio.

\footnotetext{
${ }_{18}$ Antes de testar o "método de Rousseau” com os pobres, Pestalozzi já o testara com o próprio filho (VILCHES \& COZZI, 1966, p. 14).
}

Filosofia e Educação - ISSN 1984-9605 - Volume 4, Número 2

Outubro de 2012 - Março de 2013 
O prólogo de Leonardo e Gertrudes propõe a "imitação da natureza" como base de seu enredo. Neste texto, Pestalozzi (apud VILCHES \& COZZI, 1966, p. 24) afirmou:

Tratei de embasar, tanto a história que os apresento quanto os ensinamentos que dela se depreendem, na imitação da natureza, modelo ao qual procurei ajustar-me tão escrupulosamente quanto me foi possível, não relatando senão o que acontece em toda parte.

Entre 1798 e 1799, com sua experiência prática em Stans na Suíça, lidando com crianças muito pobres, em péssima situação de higiene e saúde, Pestalozzi (1996, p. 144) também se propôs seguir tão somente a natureza ${ }^{19}$. No entanto, a imitação propugnada pelo pedagogo suíço não se limitava à natureza, mas também à educação doméstica. Ao descrever suas metas com a estadia em Stans, Pestalozzi revelou:

Minha convicção e meu objetivo eram um só. Na verdade, eu pretendia provar, com minha experiência, que as vantagens da educação familiar devem ser reproduzidas pela educação pública e que a segunda só tem valor para a humanidade se imitar a primeira (1996, p. 144).

Pestalozzi, ainda que tenha trilhado um percurso todo próprio para chegar a formular sua autêntica teoria, inspirou-se certamente em Rousseau para suas investidas científicas ${ }^{20}$. Se Rousseau teve a burguesia e a nobreza

\footnotetext{
${ }^{19}$ Comentando a diferença entre sua concepção pedagógica e a dos demais membros do Instituto de Stans, Pestalozzi registrou em carta: "[Todos] resistiram, sobretudo, à ideia e à possibilidade de não recorrer a nenhum recurso artificial, de se usar apenas como recurso educativo a natureza à volta da criança, as necessidades diárias e sua atividade, sempre animada" (1996, p. 143-4).

${ }^{20}$ A intenção aqui não é fazer de Pestalozzi um completo imitador de Rousseau. O pedagogo - como seus intérpretes defendem - deve ser concebido como "a transição, o passo entre iluminismo francês e o idealismo alemão" (INCONTRI, 1996, p. 18).
}

Filosofia e Educação - ISSN 1984-9605 - Volume 4, Número 2

Outubro de 2012 - Março de 2013 
em vista quando escreveu o Emílio (e só depois, com Emílio e Sofia ou Os solitários colocaria seu aluno ideal na dureza do mundo), Pestalozzi e seu Leonardo e Gertrudes se instalaram na perspectiva do povo e do miserável, continuando a mesma educação de Rousseau e, inclusive, submetendo-a a uma tarefa prática.

Após a experiência de Stans, em sua obra Como Gertrudis educa seus filhos (1801), Pestalozzi simultaneamente reorienta e continua o projeto do autor do Emílio. Para o pedagogo, não é um garoto extraído da aristocracia que se tona a peça central do romance e da atividade educacional prática, mas uma comunidade pobre ${ }^{21}$; seu herói não é o aluno ou o aprendiz, mas o educador, ou melhor, a educadora. Contudo, o interesse é idêntico ao de Rousseau: a imitação da natureza e a assunção da própria natureza como mestra da educação.

Froebel, considerado "seguidor de Pestalozzi", embora não cite diretamente Rousseau, parece ter lido o Emílio e outras obras do filósofo, o que se nota pela proximidade de suas teorias com as do pensador de Genebra (EBY, 1970, p. 434). Segundo Piaget (1998, p. 146), Froebel mantém o ideal de Rousseau, propondo um modelo de desenvolvimento infantil espontâneo, efetuado em liberdade, enleado às coisas e não aos livros.

Claparède, criador do Instituto Jean-Jacques Rousseau em Genebra, segue também a inspiração fundamental do Emílio. Certa vez ele afirmou: "É uma verdade elementar que a pedagogia tem que se fundamentar no conhecimento da criança, da mesma maneira que a horticultura repousa

\footnotetext{
${ }^{21}$ A preocupação pestalozziana de focar o "pobre" não revela, nem de longe, uma "proletarização" da pedagogia. Ao contrário, Pestalozzi esteve consoante, no plano educativo, à dinâmica do modo de produção capitalista, presente na transição do século XVIII ao XIX. Se ele opera com a pobreza, é eminentemente em caráter assistencialista, sem questionar as bases econômicas da produção da miséria, cf. Arce (2002).
}

Filosofia e Educação - ISSN 1984-9605 - Volume 4, Número 2

Outubro de 2012 - Março de 2013 
sobre o conhecimento das plantas" (CLAPERÈDE apud BANKS-LEITE, 1998, p. 10).

Como se manifesta a partir destes argumentos, Rousseau e sua obra foram levados adiante por estudos nos quais alguns homens de ciência se dedicaram a atestar suas teorias em casos particulares ${ }^{22}$. Não, como ele previa, somente na classe dominante, mas também no povo e na educação popular.

\section{Conclusão}

O Emílio e seu conteúdo, tanto como texto filosófico (na forma de um tratado), quanto na forma de romance pode ser, de fato, interpretado como faz a tradição idealista de Kant e Cassirer, no entender Starobinski (1991, p. 43). Para esta tendência típica do idealismo, o Emílio seria o "elo necessário" entre o segundo Discurso e o Contrato Social; a primeira obra conteria um caráter crítico e destrutivo da ordem estabelecida e a segunda se caracterizaria por seu aspecto construtivo e positivo ${ }^{23}$.

De fato, é impossível deixar de reconhecer que Rousseau capturou, em sua essência, a transformação histórica que o capitalismo industrial e a ascensão da burguesia impunham à concepção social da infância de seu tempo. Por mais que o autor tenha insistido que sua obra teve por objeto envolver a teoria da "bondade humana original" (como ele mesmo afirmou no terceiro dos Diálogos de Rousseau, juiz de Jean-Jacques) e tratar de seu sistema que descreve a "marcha da natureza" (como garante o prefácio do $E_{\text {Emílio }}{ }^{24}$, foi por sua constituição histórica em um período de profundas

${ }^{22}$ Poderíamos citar, além dos pensadores já mencionados neste artigo, Célestin Freinet; sobre a aplicação prática das ideias de Rousseau na obra de Freinet, cf. Cabral (1978).

${ }^{23}$ Starobisnki (1991, p. 41) menciona a leitura materialista de Rousseau, efetuada por Engels. Segundo esta concepção, a síntese das obras de Rousseau não teria como elo a educação do Emílio, mas a ideia de revolução.

${ }^{24}$ São temas, como se nota, de natureza puramente filosófica. Cf. também o início do Livro I do Emílio, quando Rousseau escreve: "Nosso verdadeiro estudo é o da condição humana" (2004, p. 15).

Filosofia e Educação - ISSN 1984-9605 - Volume 4, Número 2

Outubro de 2012 - Março de 2013 
transformações no campo cultural que sua obra pedagógica se construiu como modelo de texto pedagógico.

O que confere valor pedagógico ao Emílio é, sem dúvida, a constatação de que a obra foi lida ao longo dos séculos como um tratado pedagógico sobre a infância e sua educação, quando, na verdade, foi escrita com uma finalidade autenticamente filosófica. Além da advertência de Rousseau - já discutida aqui - logo no fim do prefácio do Emílio, o filósofo ainda repete sua completa isenção de quaisquer ambições práticas no percurso do Livro I, ao afirmar:

Sem condições de cumprir a tarefa mais útil, ousarei pelo menos tentar a mais fácil. A exemplo de muitos outros, não porei mãos à obra, mas à pluma e, em lugar de fazer o que se deve, empenharme-ei em dizê-lo.

Esta convicção de Rousseau, ao não ter sido observada pelos leitores pedagogos, permitiu que a obra fosse redefinida e, inclusive, criticada à luz daquilo que o autor não se dispôs a fazer.

Apesar do belo esforço histórico de colocar Rousseau na ordem do processo histórico-pedagógico que ajudou a construir os métodos novos em pedagogia, Piaget lê o autor do Emílio como se ele tivesse desejado por em prática suas ideias.

Analisando a contribuição de Rousseau para o aparecimento dos chamados "métodos novos", Piaget (1998, p. 143) discute as ideias do filósofo de Genebra sobre o desenvolvimento intelectual da criança e escreve:

[...] essa intuição contínua da realidade do desenvolvimento mental é por enquanto nele [em Rousseau] apenas uma crença sociológica, algumas vezes instrumento polêmico; se ele mesmo tivesse estudado as leis dessa maturação psicológica, da qual sempre

Filosofia e Educação - ISSN 1984-9605 - Volume 4, Número 2

Outubro de 2012 - Março de 2013 
postula a existência, não teria dissociado a evolução individual do meio social.

Piaget, em uma análise aparentemente anacrônica, reivindica a Rousseau o estudo das "leis de maturação" da cognição infantil na interação indivíduo-sociedade, o que, como todos sabem, negaria profundamente o princípio básico da filosofia de Rousseau: o de que imiscuída à natureza, a criança é inevitavelmente corrompida.

Mais adiante, Piaget (1998, p. 144-5) prossegue:

O que faltou ao rousseauísmo, para chegar a construir uma pedagogia científica, foi uma psicologia do desenvolvimento mental. [...] [Em Rousseau não há] nada de uma embriologia real da inteligência e da consciência, que mostre como as funções se transformam qualitativamente no curso do dinamismo contínuo de sua elaboração.

Nesta passagem Piaget se vale daquilo a que Rousseau não se propôs a fazer para demonstrar o que ele mesmo, Piaget, fez com seus estudos em psicologia: criar uma "psicologia do desenvolvimento", mostrar a gênese das estruturas da inteligência, evidenciando suas contínuas transformações.

Após afirmar (equivocadamente) que Rousseau não teve nenhuma experiência prática lecionando para crianças (1998, p. 17), Piaget questiona a famosa afirmação de que Rousseau seria o "Copérnico da pedagogia", justificando que ele só mereceria este título se "tivesse precisado em que consiste este caráter ativo da infância” que tanto divulgou (p. 148).

Os equívocos e descuidos histórico-filosóficos da leitura de Rousseau efetuada pelos pedagogos e pelos psicólogos do desenvolvimento infantil (do qual Piaget é, certamente, um grande exemplo) nos faz concluir que não se pode exigir que a contribuição de Rousseau para a educação seja necessariamente prática. No entanto, é preciso ter em vista que se a 
pedagogia se desenvolveu tanto após o Emílio, isso se deve justamente aos ganhos obtidos com esta leitura pedagógica da obra, que se faz, de fato, pela imprecisão histórico-filosófica ou pela incerta reivindicação daquilo que falta a uma obra para cumprir aquilo a que ela não se propõe.

A partir do percurso aqui desenvolvido, conclui-se que a leitura do Emílio em cursos de formação de professores deve ser feita compreendendo-se essa profusa miscelânea de gêneros literários: o tratado filosófico, o romance e o texto pedagógico. Não basta, pura e simplesmente, colocar o Emílio nas mãos dos estudantes de licenciatura, para que sua leitura cumpra o papel formativo que pode desempenhar. É necessário mostrar-lhes que houve todo um caminho trilhado pelo autor para que sua obra tivesse o impacto que teve sobre a história das ideias pedagógicas. Trata-se, portanto, de uma obra densa, que, segundo o próprio criador, unese ao primeiro e ao segundo Discurso, formando um todo conjunto ${ }^{25}$.

Se não for explicitada a maneira pela qual esta obra impactou Pestalozzi, Froebel, Claparède e outros grandes nomes da educação moderna, o estudo do Emílio certamente continuará, apesar de seu profundo sentido pedagógico, um livro a ser mencionado apenas pelos manuais de História da Educação, permanecendo, assim, reduzido, distorcido, decorado e quase esquecido.

\section{Referências bibliográficas}

ARCE, A. Documento oficial e o mito da educadora nata na Educação Infantil. Cadernos de Pesquisa, São Paulo, no 113, p. 167-184, julho de 2001.

- A pedagogia na "era das revoluções": uma análise do pensamento de Pestalozzi e Froebel. Campinas: Autores Associados, 2002.

ARIÈS, Ph. História social da criança e da família. Tradução: Dora Flaksman. Rio de Janeiro: Zahar, 1981.

\footnotetext{
${ }^{25}$ Seguindo a interpretação de Fortes (1976, p. 71), o Contrato social seria, inclusive, uma espécie de continuação do Emílio, na medida em que completaria "a formação do homem Emílio ou a do cidadão". A obra teria, nessa perspectiva, também uma "importância pedagógica".
} 
BANDINTER, E. Um amor conquistado: o mito do amor materno. Tradução: Waltensir Dutra. Rio de Janeiro: Nova Fronteira, 1985.

BANKS-LEITE, L. (org.) Piaget e a escola de Genebra. São Paulo: Cortez, 1998. BURGELIN, P. Émile. In: ROUSSEAU, J.-J. Oeuvres complètes. Paris: Gallimard, 1969, pp. LXXXVIII-CLII.

CABRAL, M. De Roussean a Freinet on Da teoria à prática. São Paulo: Hemus, 1978.

COMPAYRÉ, G. Histoire critique des doctrines de l'éducation en France depuis le seizième siècle. Genève: Slatkine, 1970.

COSTA, W. Émile e os males do mundo. In: ROUSSEAU, J.-J. Émile e Sophie ou Os solitários. Tradução: Françoise Galler. Florianópolis: Paraula, 1994.

EBY, F. História da educação moderna. Tradução: Maria Ângela Almeida, Nelly Maia e Malvina Zaide. Porto Alegre: Globo, 1970.

FORTES, L. Rousseau: da teoria à prática. São Paulo: Ática, 1976.

FREITAG, B. O indivíduo em formação. São Paulo: Cortez, 1994. Coleção Questões da nossa época, 30.

GHIRALDELLI, P. O que é pedagogia? São Paulo: Brasiliense, 1987.

HUBERT, R. História da pedagogia. Tradução: Luiz e J. B. Damasco Penna. São Paulo: Editora Nacional; Brasília: INL, 1976. Coleção Atualidades Pedagógicas, 66.

INCONTRI, D. Pestalozæi: educação e ética. São Paulo: Scipione, 1996.

JIMACK, P. La genèse et la rédation de l'Émile de J.-J. Rousseau: étude sur l'histoire de l'ouvrage jusq'à sa parution. Genebra, 1960.

LUZURIAGA, L. História da educação e da pedagogia. Tradução: Luiz e J. B. Damasco Penna. São Paulo: Companhia Editora Nacional, 1972.

MARQUES, J. Apresentação. In: ROUSSEAU, J.-J. Carta a Christophe de Beaumont e outros escritos sobre a religião e a moral. São Paulo: Estação Liberdade, 2005, p. 9-16.

MORNET, D. Rousseau: l'homme et l'oeuvre. Paris: Boivin, 1950.

MORETTO, F. Introdução. In: ROUSSEAU, J.-J. Os devaneios do caminhante solitário. Tradução: Fúlvia Moretto. Brasília: Editora da UnB, 1986, p. 7-17.

Introdução. In: ROUSSEAU, J.-J. Júlia ou a Nova Heloísa. Tradução:

Fúlvia Moretto. São Paulo: Hucitec; Campinas: Editora da Unicamp, 1994b.

NACARATO, P. Roussean nos cursos de formação de professores: conhecimento ou distorção? 2008. Tese (Doutorado). Faculdade de Educação, Universidade de São Paulo, São Paulo.

PESTALOZZI, J. Carta de Stans. In: INCONTRI, D. Pestalozzi: educação e ética. São Paulo: Scipione, 1996, p. 140-158.

PIAGET, J. Psicologia e pedagogia. Rio de Janeiro: Forense Universitária, 1998.

PY, G. Rousseau et les educateurs. Oxford : Voltaire Fondation, 1997.

ROUSSEAU, J.-J. As confissões. Tradução: Wilson Lousada. São Paulo: Ediouro, $\mathrm{s} / \mathrm{d}$.

Filosofia e Educação - ISSN 1984-9605 - Volume 4, Número 2

Outubro de 2012 - Março de 2013 
- Os devaneios do caminhante solitário. Tradução: Fúlvia Moretto. Brasília: Editora da UnB, 1986, p. 7-17.

Projeto para a educação do senhor de Sanite-Marie. Tradução: Dorothée de Bruchard. Florianópolis: Paraula, 1994a.

Júlia on a Nova Heloísa. Tradução: Fúlvia Moretto. São Paulo: Hucitec; Campinas: Editora da Unicamp, 1994b.

- Emílio on Da educação. Tradução: Roberto Leal Ferreira. São Paulo: Martins Fontes, 2004.

Cartas a Malesherbes. Tradução: Maria Cecília Pinto. In: Carta a

Christophe de Beaumont e outros escritos sobre a religião e a moral. São Paulo: Estação Liberdade, 2005, p. 17-36.

Cartas escritas da montanha. Tradução: Maria Constança Pissarra e Maria das Graças de Souza. São Paulo: EDUC; UNESP, 2006.

STAROBINSKI, J. Jean-Jacques Rousseau: a transparência e o obstáculo. Tradução: Maria Lúcia Machado. São Paulo: Companhia das Letras, 1991.

STRECK, D. Rousseau e a educação. Belo Horizonte: Autêntica, 2008.

VILCHES, G. \& COZZI, V. La educación en Pestalozzi y Froebel. Buenos Aires: Huemul, 1966.

YOLTON, J. \& YOLTON, J. Introduction. In: LOCKE, J. Some Thoughts Concerning Education. New York: Oxford University Press, 1989, p. 1-26. 